\title{
MORALIDADE, JUSTIFICAÇÃO E COERÊNCIA
}

\author{
Denis Coitinho* \\ deniscoitinhosilveira@gmail.com
}

RESUMO Neste artigo pretendemos mostrar as vantagens do modelo epistemológico coerentista quando aplicado ao universo moral. O ponto de partida será apontar que a justificação da crença moral é dada pela coerência com um sistema coerente de crenças que é consistente e que isso pretende resolver o problema da dicotomia entre fato e valor. Posteriormente, apresentam-se as características centrais do coerentismo holístico e investiga-se o método do equilíbrio reflexivo. O próximo passo será fazer referência a três conhecidas objeções ao coerentismo, a saber: o problema do isolamento, os sistemas coerentes alternativos e a circularidade viciosa. Por fim, procuramos responder a essas objeções apelando para os seguintes argumentos: holismo social, razoabilidade e estabilidade social.

Palavras-chave Coerentismo holístico, Equilibrio reflexivo, Holismo social, Razoabilidade, Estabilidade social.

ABSTRACT In this paper we aim to demonstrate the advantages of the epistemological coherentist model when applied to the moral sphere. The starting point will be to show that the justification of moral belief is a matter of how beliefs fit together with a coherent system of beliefs that is consistent and that it tries to solve the issue of the fact/value dichotomy. Following this, we shall point out the core characteristics of the holistic coherentism and 
we will investigate the reflective equilibrium method. Next step is to show three standard objections to coherentism, namely, the isolation problem, the alternative coherent systems objection and the vicious circularity. Finally, we shall then try to respond these criticisms with the following arguments: social holism, reasonableness and social stability.

Keywords Holistic coherentism, Reflective equilibrium, Social holism, Reasonableness, Social stability.

\section{I}

Imaginemos dois amigos, Beto e Augusto, discutindo sobre a moralidade das relações homoafetivas, sobretudo, discutindo sobre a pertinência de suas uniões estáveis e da possibilidade da adoção de filhos para a constituição de uma família. Nessa discussão, Beto defende que as relações homoafetivas são corretas do ponto de vista moral. Augusto, por sua vez, discorda, alegando que essas relações afetivas são imorais e, portanto, não seria adequado que o Estado permitisse a sua união estável e nem permitisse que casais desse tipo pudessem adotar filhos para constituírem uma família. Augusto alega que esse tipo de relação contraria uma orientação natural e que uma família é composta por um casal e seus respectivos filhos, sendo um casal formado exclusivamente por um homem e uma mulher. É isso que ele aprendeu com seus pais, está escrito na Bíblia e, inclusive, está amparado pela Constituição brasileira, conforme lembra ter lido a respeito no jornal. Beto, por outro lado, busca justificar a correção moral das relações homoafetivas apontando para uma coerência desse juízo com os princípios constitucionais que garantem a igualdade e a liberdade de todos. $\mathrm{O}$ artigo $5^{\circ}$ da Carta constitucional brasileira, ao elencar os direitos e garantias fundamentais, proclama: "todos são iguais perante a lei, sem distinção de qualquer natureza". Também, o preâmbulo da Declaração Universal dos Direitos Humanos reconhece que a "dignidade inerente a todos os membros da família humana e dos seus direitos iguais e inalienáveis constitui o fundamento da liberdade, da justiça e da paz no mundo". Além da coerência desse juízo moral com esses princípios identificados na Constituição do Brasil e na Declaração Universal dos Direitos Humanos, Beto procura esclarecer que as evidências dadas hoje pela medicina e pela psicologia apontam que há uma orientação natural homoafetiva, não se tratando propriamente de uma escolha voluntária do agente. O ponto central do argumento de Beto é que, dado que Augusto aceite os princípios de igualdade e liberdade contidos na 
Constituição e na Declaração Universal e, dado que ele pode se atualizar em relação aos fatos científicos em questão, ele deveria aceitar a moralidade das relações homoafetivas. Como Augusto realmente aceita esses princípios que garantem a liberdade e igualdade de todos e consegue compreender as novas evidências dadas pela ciência, ele aceita o argumento de Beto e passa a ter dúvidas do seu juízo anteriormente proferido.

Mais tarde, não conformado em ter tido que abandonar tão facilmente o seu julgamento moral, Augusto se matricula em um curso intensivo de epistemologia a fim de melhor compreender como se dá o processo do conhecimento científico, sua natureza e limites. Aprende sobre os diversos modelos de justificação de crenças, tais como o coerentista, o fundacionista, o contextualista e o fundacionista moderado etc. Estuda com especial atenção as fraquezas do modelo coerentista e no próximo encontro com Beto retoma a discussão anterior. Pergunta para Beto se a sua afirmação de que "as relações homoafetivas são corretas moralmente" não refletiria apenas o próprio preconceito de Beto, uma vez que um sistema coerente de crenças poderia ser somente uma ficção e não guardar nenhuma semelhança como mundo externo? Faz notar que o artigo 226 da Constituição brasileira, em seu $\S 3^{\circ}$, define a família como uma "união estável entre o homem e a mulher", da mesma forma que o faz o artigo 16 da Declaração Universal dos Direitos Humanos e que, além disso, existiriam evidências de que casais homoafetivos não poderiam constituir família uma vez que não poderiam procriar. Também, pergunta para Beto como fazer para escolher entre sistemas coerentes alternativos, pois, ressalta, que também parece haver coerência entre a crença que diz que "relações homoafetivas são imorais", o artigo constitucional que define a família como uma união formada por um homem e uma mulher, além do artigo da Declaração Universal que também define a família da mesma maneira, e a crença religiosa que proíbe "deitar-se com um homem como se faz com uma mulher", que se pode encontrar no Antigo Testamento (Levítico, $18,22)$. Essa escolha não seria arbitrária? Por fim, pergunta para Beto se seu argumento não seria circular, uma vez que a justificação da crença moral se daria apenas por sua coerência com um princípio e com uma crença não moral. Onde estaria realmente o fundamento normativo desse juízo? Ele não teria que ser verdadeiro para estar justificado? E essa verdade não deveria estar ancorada em um fato com certas características apropriadas?

O exemplo acima procurou ilustrar as dificuldades que encontramos quando nos perguntamos sobre a maneira de justificar adequadamente certas crenças morais em nossos discursos comuns. Cotidianamente ouvimos e proferimos juízos morais que afirmam ou negam a moralidade de certos 
atos, tais como o aborto, eutanásia, casamento homoafetivo, distribuição de riquezas etc. O problema se dá, sobretudo, quando tentamos justificar nossas crenças aos outros que discordam de nós ou até para nós mesmos quando estamos em dúvida. O que faria um ato ser tomado como certo ou errado? Precisaríamos necessariamente justificar uma crença moral a partir de certos princípios morais que seriam correspondentes a alguma propriedade moral como a "correção" ou o "erro"? Ou, alternativamente, bastaria que pudéssemos apontar para a coerência entre juízos morais, princípios e outras crenças não morais para termos a justificação? Seriam essas crenças e princípios morais revisáveis ou eles teriam a sua objetividade garantida especificamente pelo seu caráter fixo?

Embora já reconhecendo que não conseguiremos responder a todas essas questões anteriormente formuladas, o objetivo central deste texto é procurar mostrar a força do coerentismo para o âmbito moral. Especificamente, queremos ressaltar como o coerentismo, quando aplicado ao caso moral, pode oportunizar um modelo mais eficiente para a justificação de crenças ao evitar os problemas epistemológicos do fundacionismo, tais como o dualismo, o dogmatismo e principalmente a assimetria entre fatos e princípios morais, de um lado, em contraposição às crenças morais asseguradas pelos agentes, de outro. Também, procuraremos apontar que o coerentismo de tipo holístico consegue evitar o regresso epistêmico e apresentar uma solução ao problema da dicotomia entre os fatos e os valores ao estabelecer uma relação de reciprocidade na direção entre as regras e os casos, e que isso parece ser relevante ao observarmos o pluralismo moral de sociedades contemporâneas. Para tal finalidade, procuraremos responder às principais críticas endereçadas ao coerentismo, a saber, a crítica ao isolamento, aos sistemas coerentes alternativos e à circularidade, a fim de verificar se o coerentismo seria um modelo epistemológico adequado para se pensar a respeito da justificação de crenças morais ou se ele deveria ser integralmente abandonado em razão de suas supostas fraquezas.

\section{II}

Antes de procurarmos responder a essas três importantes críticas endereçadas ao coerentismo, pensamos ser importante esclarecer o que estamos compreendendo por um modelo coerentista de justificação e sua aplicação ao universo moral. Uma definição ampla que se pode estabelecer incialmente e que parece se acomodar com as diversas posições coerentistas poderia ser a seguinte: para o coerentismo, uma crença estará justificada se ela 
estiver em harmonia ou for coerente com um sistema coerente de crenças ou com um sistema coerente de crenças, proposições, testemunhos e memórias. Por exemplo, a minha crença de que hoje "vai chover" e, então, que eu "devo levar o guarda-chuva", estaria justificada por sua harmonia com a previsão do tempo que li no jornal e que anunciava chuva para a tarde e, também, com a constatação do tempo nublado quando olhei pela janela, e isso em conexão com minha lembrança que geralmente chove quando está nublado. Mas o que isso significaria especificamente se considerarmos apenas o âmbito moral e não o universo de crenças sobre o mundo exterior?

No âmbito da moralidade, o coerentismo parece defender que uma crença moral estará justificada se ela estiver em harmonia ou for coerente com um sistema coerente de crenças, e isso implicaria apontar para a coerência da crença moral com algum padrão normativo, tal como um princípio moral ou uma virtude, além de uma harmonia com crenças factuais que procuram descrever o mundo objetivamente. Um conhecido exemplo de aplicação do coerentismo na filosofia moral pode ser encontrado na teoria da justiça como equidade de John Rawls, dado o importante papel que o método do equilíbrio reflexivo desempenha para a obtenção da justificação de crenças morais. As crenças de que "a intolerância religiosa" e a "discriminação racial são injustas" estariam justificadas por sua coerência com princípios morais-políticos de liberdade, igualdade e bem comum que seriam escolhidos pelas partes em uma posição de simetria, além de serem coerentes com crenças factuais a respeito das pessoas serem morais e a sociedade ser um empreendimento cooperativo. De forma similar, um agente poderia estar justificado em assegurar a crença de que "a intolerância religiosa é injusta" apelando para a coerência dessa crença moral com um sistema coerente de crenças. ${ }^{1}$

Dois esclarecimentos se fazem necessários antes de avançarmos na tentativa de elucidar as características centrais do coerentismo no âmbito moral. O primeiro é que a verdade não precisará ser tomada como uma

1 Veja-se que a coerência seria encontrada entre (i) os juízos morais ponderados, como os que afirmam que a escravidão e a intolerância religiosa são injustas, (ii) os princípios de justiça que afirmam a liberdade igual, a igualdade equitativa de oportunidade e a diferença específica e entre (iii) as teorias de fundo relevantes, particularmente a teoria da pessoa como moral, a teoria da justiça procedimental, a teoria social geral e a teoria do papel da moralidade na sociedade, incluindo a ideia de sociedade bem ordenada. É o nível III (Teorias) que persuadiria o agente a adotar o aparato contratual com suas restrições (Nível II). Também, os princípios escolhidos no Nível II teriam duas restrições: (a) devem ser coerentes com os nossos juízos ponderados em equilíbrio reflexivo parcial e (b) devem garantir uma sociedade estável. Ver: Daniels, 1979, p. 260. Rawls explica o equilíbrio reflexivo como um método de investigação das concepções morais substantivas asseguradas pelas pessoas. Em suas palavras: "Para fazer isso, se tenta encontrar um esquema de princípios que se harmonizem com os juízos ponderados e as convicções gerais das pessoas em equilíbrio reflexivo" (Rawls, 1999a, p. 288). Ver, também, Rawls, 1999b, pp. 15-19. 
condição necessária para a justificação da crença, e o segundo é que estamos entendendo o coerentismo como holístico e não como linear. Comecemos por esse último. No caso do coerentismo linear, a justificação de uma crença $p$ se daria em razão de sua coerência com outra crença $q$, que, por sua vez, estaria justificada por sua coerência com outra crença $r$, e assim sucessivamente. A insuficiência desse modelo linear é que ele não resolve de maneira adequada o problema regresso ao infinito, uma vez que o processo justificacional se daria em uma cadeia infinita de crenças, o que inviabilizaria a identificação de objetividade para a justificação. Isso parece não ocorrer no modelo holístico de coerentismo, uma vez que a crença se justificará por sua harmonização com um sistema coerente como um todo, sendo um sistema coerente de crenças um conjunto de crenças que possui consistência lógica. Dessa forma, não haveria um regresso ad infinitum no processo de justificação da crença, bem como o sistema consistente de crenças poderia ser tomado como o fundamento para essa justificação da crença, o que parece garantir a sua objetividade.

O segundo esclarecimento importante é que em uma teoria coerentista de justificação o que importa é ver o que pode justificar uma crença $p$ ou ver o que seria para um agente $S$ estar justificado em assegurar uma crença $p$ ou um conjunto de crenças. Por exemplo, o que poderia justificar a crença de que "a tolerância religiosa é boa" e "a tortura é má" ou, alternativamente, de que forma um agente $S$ poderia estar justificado em assegurar que a "tolerância religiosa é boa" e "a tortura é má"? Uma teoria moral coerentista poderia explicar que o agente estaria justificado em assegurar a bondade ou correção da tolerância religiosa e a maldade ou erro da tortura em razão da harmonia dessas crenças com os princípios morais da dignidade humana e autonomia que, por sua vez, estariam harmonizados com crenças genéricas sobre o valor da liberdade e igualdade das pessoas que constam em um modelo político liberal professado pelos cidadãos em democracias contemporâneas, por exemplo. De outro lado, para uma teoria coerentista da verdade importaria mostrar o que significa para uma crença $p$ ser verdadeira ou, alternativamente, mostrar de que forma um agente $S$ saberia que tal crença $p$ é verdadeira.

Há uma distinção importante aqui, uma vez que, para uma teoria coerentista da verdade, a justificação seria obtida pela verdade da crença, ao passo que, para uma teoria coerentista da justificação, poderíamos obter a justificação para as crenças de forma independente de sua verdade. Vejamos um interessante exemplo dado por Russell a esse respeito: "Otelo acredita que Desdêmona ama Cássio". A crença de Otelo que "Desdêmona ama Cássio" é coerente, mas não é verdadeira, pois não haveria algo como "o amor de Desdêmona por Cássio". A coerência aqui é insuficiente 
para o estabelecimento da verdade; entretanto, pode auxiliar para se obter conhecimento. ${ }^{2}$ Por exemplo, em razão das evidências observadas, como a do lenço de Desdêmona ter sido encontrado com Cássio e de Iago ter insinuado que Desdêmona o estava traindo, Otelo estaria justificado em desconfiar da traição e buscar esclarecimentos. Entretanto, não estaria justificado em matála, uma vez que também seria coerente atribuir o ocorrido à inveja de Iago. No âmbito deste trabalho, iremos tomar o coerentismo apenas no domínio de uma teoria da justificação e não no domínio de uma teoria da verdade, e isso em razão de tomarmos o conhecimento, no âmbito moral, como um conjunto coerente de crenças morais justificadas preferencialmente do que entendê-lo como o conjunto de crenças verdadeiras e justificadas.

Dito isso, podemos identificar que uma epistemologia moral coerentista holística assegura que uma crença moral é justificada na medida em que o conjunto de crenças do qual ela faz parte é coerente. Assim, cada crença moral é avaliada pelo papel que ela desempenha no conjunto coerente das crenças, evitando o problema do regresso epistêmico. Se a coerência do conjunto for fortalecida pela exclusão de uma crença ou mesmo pela substituição de uma crença oposta, a crença em questão não será justificada. Entretanto, se o conjunto for mais coerente com a presença de uma crença preferencialmente a qualquer outra crença alternativa, então, essa primeira crença estará justificada. Nesta forma de conceber a justificação coerentista de maneira holística, não haverá a presença de pontos fixos dos quais outras crenças seriam inferidas. Cada crença é avaliada pela consideração do efeito de sua presença no sistema coerente, sendo testada por sua efetividade no sistema ${ }^{3}$ e, também, de forma a contar como uma razão em uma situação específica. ${ }^{4}$ Assim, a justificação

2 Importante frisar que Russell está tomando o conhecimento não como o conjunto de crenças verdadeiras e justificadas, mas como o conjunto de opiniões prováveis. Dessa forma, a coerência, embora insuficiente para possibilitar a verdade, pode auxiliar no processo para se obter conhecimento. Ver: Russell, 1912, pp. 186-219. A respeito de esse problema da coerência ser insuficiente para verdade, é interessante fazer referência à posição de Olsson, que identifica que as principais críticas ao coerentismo são mal fundadas, pois têm por foco uma concepção proposicional de verdade e não uma concepção doxástica ou testemunhal. Com esta última forma de compreensão, a coerência poderia ser vista como um melhor condutor à verdade em um sentido mais fraco. Ver: Olsson, 2002, pp. 247-248, 272.

3 Essa forma de justificação está associada ao holismo semântico de Quine, que busca superar a dicotomia entre as proposições analíticas e sintéticas, contrapondo-se ao atomismo e ao empirismo reducionista. Dessa forma, não haveria um fundo experiencial próprio para cada sentença, uma vez que apenas teorias abrangentes possuiriam significância. Assim, nenhum enunciado, tomado isoladamente de seus pares, admitiria confirmação. Para Quine, nossos enunciados comparecem ao tribunal da experiência sensível como um corpo integrado e não de forma isolada (Quine, 1953, p. 41). Ver, também, Quine, 1969, pp. 6990.

4 Outra forma de ver o holismo é associá-lo a uma concepção moral particularista, de forma que uma determinada característica que seria uma razão em um caso poderia não ser uma razão em outro. Aqui o holismo está se contrapondo igualmente ao atomismo, além de estar se contrapondo ao generalismo. Ver: Dancy, 2004, pp. 1-12. Entretanto, essa vinculação do holismo ao particularismo não é obrigatória, 
da crença moral não seria uma questão de correspondência a um fato moral ou uma dedução de premissas autoevidentes, mas seria uma questão de apoio mútuo entre juízos, virtudes e princípios morais no interior de um sistema coerente de crenças, isto é, no interior de um sistema consistente de crenças morais e não morais. ${ }^{5}$

A partir das características identificadas acima, creio que podemos apresentar o modelo de justificação moral coerentista por meio da seguinte formulação:

Uma crença moral $p$ estará justificada para um agente $S$ em um tempo $t$ e em circunstâncias $C$ se e somente se ela for coerente com um sistema consistente de crenças $C S{ }^{6}$

\section{III}

$\mathrm{Na}$ seção anterior, procuramos definir o que estamos compreendendo por coerentismo holístico e, também, buscamos identificar as características específicas de uma epistemologia moral coerentista, ressaltando os principais problemas que poderiam ser resolvidos com esse modelo epistemológico aplicado ao âmbito moral. Mas faltou refletir de maneira mais cuidadosa a respeito das possíveis fraquezas dessa abordagem. Nesta seção, buscaremos apontar para as principais objeções que são feitas ao coerentismo em geral e ao coerentismo moral em particular, a fim de analisar mais detalhadamente o seu alcance.

Uma primeira objeção que comumente é endereçada ao coerentismo é a respeito de como um sistema internamente coerente se relaciona com o mundo externo. Veja-se que uma ficção é um sistema coerente, mas pode não guardar muita semelhança com o mundo externo, permanecendo apenas

uma vez que encontramos concepções holistas que estariam conectadas ao generalismo. Ver a posição de Luke Robinson, por exemplo. Para ele, o holismo moral pode ser visto como uma forma de generalismo moral que toma os fatos sobre o correto para explicar certos fatos morais particulares, a saber, a correção e o erro das ações particulares. A regra é: $O$ peso e a valência de um fato $F$ em circunstâncias $C$ pode ser afetado por outros fatos que $F$ ele mesmo. Ver: Robinson, 2006, pp. 332-335.

5 Para Bonjour, a tese central do coerentismo holístico é (i) a da não existência de crenças fundacionais ou básicas e (ii) que a base para a justificação se funda no fato de que as crenças se harmonizam em conjunto e apoiam-se mutuamente, formando um sistema coerente de crenças. Assim, a justificação coerentista possuiria as seguintes características: (a) essa justificação não é linear, (b) ela deve ter consistência, (c) estar fundada na observação e (d) não possuir uma metacrença (Bonjour, 2008, pp. 42-53). Sobre a dependência de uma ontologia genérica que seria característica de qualquer modelo coerentista holístico, ver: Esfeld, 1998, pp. 367-371. Voltaremos a esse ponto posteriormente.

6 Keith Lehrer apresenta a seguinte fórmula de uma teoria coerentista de justificação: " $S$ está inteiramente justificado em aceitar que $p$ se e somente se a crença que $p$ for coerente com outras crenças que pertencem a um sistema $C$ de crenças de tipo k" (Lehrer, 1990, p. 87). 
como uma ficção. Um livro ou filme que retrata uma situação planetária futura pós-hecatombe nuclear, em que uma civilização de macacos oprime seres humanos, pode ser coerente, mas isso não traz por consequência, necessariamente, que encontraremos macacos tratando os seres humanos como animais e governando o nosso mundo presente. Essa crítica é conhecida como o problema do isolamento ou a objeção ao input. Essa objeção aponta que uma concepção de justificação que dependa inteiramente da coerência teria a consequência absurda de tomar as crenças factuais como justificadas na ausência de qualquer tipo de dado empírico e, assim, essa justificação se basearia em uma relação acidental com o mundo. ${ }^{7}$ No caso moral, isso poderia significar que as crenças usadas no sistema coerente poderiam apenas refletir nossos próprios preconceitos, não mantendo uma relação de proximidade com o mundo externo. Quer dizer, até que ponto se poderia atribuir credibilidade inicial para as crenças morais que serão usadas na construção do sistema? ${ }^{8}$

Essa objeção ao isolamento (input) aplicada ao caso moral parece questionar se o ponto de partida para uma teoria moral seria apropriado ou não. Em outras palavras, essa crítica parece revelar que o ponto inicial de uma teoria seria inapropriado em razão de estar conectado apenas com o mundo interno do agente. Quer dizer, os juízos morais com que se inicia o processo poderiam ser vistos apenas como um espelhamento de nossos preconceitos. Por exemplo, o juízo moral que afirma "a imoralidade do aborto" poderia ser apenas uma extensão do preconceito de tomar a vida humana como sagrada. Ou, alternativamente, o juízo que afirma que "a tortura é correta", no caso de ser aplicado ao contexto de detentos em um presídio, poderia não passar de uma projeção do preconceito em tomar o indivíduo como livre, isto é, como tendo livre-arbítrio e, em razão de sua escolha livre em cometer uma má ação, como matar, por exemplo, esse agente mereceria o sofrimento e, então, deveria ser exemplarmente punido.

Creio que o ponto central da crítica seja a respeito da credibilidade inicial de certas crenças que são usadas no desenvolvimento de uma teoria moral. Por que elas deveriam contar como credíveis? Apenas por sua coerência com o sistema como um todo, de forma que as convicções, princípios morais e,

7 Lawrence Bonjour reconstrói essa objeção padrão ao coerentismo (input objection) e oferece uma interessante resposta ao apontar para o relevante papel que crenças observacionais podem desempenhar para a justificação empírica no interior de um sistema coerentista. Ver: Bonjour, 2008, p. 53. Também, ver: Bonjour, 1985, pp. 139-140.

8 Richard Brandt faz uma objeção nesse sentido ao criticar o método do equilíbrio reflexivo de John Rawls, uma vez que ficções coerentes ainda continuam sendo ficções e, no caso moral, parecem apenas refletir nossos próprios preconceitos. Ver: Brandt, 1979, pp. 16-22. 
também, crenças não morais estariam em harmonia? O problema é que esse sistema coerente, por exemplo, uma teoria moral, poderia não guardar nenhuma relação com o mundo externo e, assim, por que deveríamos dar credibilidade a essas crenças iniciais? Veja-se o caso de uma teoria indeterminista da responsabilidade moral. A defesa da responsabilidade moral do agente estaria fundada na crença do livre-arbítrio do indivíduo, o que implicaria a crença de uma ação indeterminada ou até mesmo não causada, tal como a escolha livre e, isso, por sua vez, se harmonizaria com uma crença na punição retributivista. $\mathrm{O}$ todo é coerente, mas pode ser o caso de não existir algo no mundo como o livre-arbítrio. Seria essa crença no livre-arbítrio verdadeira ou estaria ela justificada apenas por sua coerência com o sistema coerente? O problema então é: por que deveríamos atribuir alguma credibilidade especial a essas convicções particulares se não se pode levar em conta nenhum tipo de fundamento ou prova que seja independente da coerência? ${ }^{9}$

Outra crítica bem conhecida é a respeito dos sistemas coerentes alternativos, isto é, dada a existência de diversos sistemas coerentes alternativos ou até mesmo incompatíveis entre si, como escolher entre eles? Tomando como referência que um sistema coerente é consistente logicamente, mas que existem diversos sistemas que são igualmente consistentes, como fazer uma escolha sem recair em algum tipo de arbitrariedade? Veja-se que as partes (crenças) consistentes de cada um desses sistemas serão tomadas como critérios para a justificação, isto é, serão tomadas como normas, uma vez que uma crença será justificada em razão de sua coerência com um sistema coerente de crenças. O problema é que isto parece resultar em um absurdo, especialmente porque cada crença relevante a uma área específica que não seja internamente incoerente pode aparentar pertencer a um ou mais sistemas, de forma que o coerentismo deveria dizer que tais crenças seriam justificadas como quaisquer outras. ${ }^{10}$

O mais grave da objeção é a pergunta sobre o que se deve fazer quando nos deparamos com um vasto número de sistemas de crenças igualmente coerentes que são incompatíveis entre si, de forma que, se um sistema for

9 Brandt faz uma crítica nesses moldes, questionando a respeito da credibilidade que se deve reconhecer a essas crenças morais iniciais em um modelo coerentista. Sua acusação é que o coerentismo acaba fazendo uso de um tipo de intuicionismo, mas não ofereceria nenhuma distinção epistemológica para creditar mais credibilidade a certas convicções morais. O ponto central é que essa abordagem implicaria conservadorismo epistêmico. Ver: Brandt, 1990, pp. 265-272. Peter Singer faz críticas semelhantes ao apontar para o perigo em se atribuir um peso excessivo para os juízos particulares intuitivos, referindo-se aos juízos ponderados no método de equilíbrio reflexivo. A esse respeito, ver: Singer, 2002, pp. 46-48.

10 Essa crítica foi apontada por Bonjour e ele também a responde fazendo uso do argumento das crenças observacionais para uma justificação empírica dentro de um quadro coerentista. Ver: Bonjour, 2008, pp. 53-54. Ver, também, Bonjour, 1985, pp. 143-146. 
tomado como padrão, o outro será visto como problemático. Isso parece significar que algo forçosamente iria além da coerência para a justificação. A questão poderia ser particularmente preocupante quando se percebe que uma mesma pessoa poderia possuir dois sistemas de crenças igualmente coerentes, mas em tempos diferentes, podendo diferir não apenas sobre um ponto, mas sobre cada ponto específico, de forma que cada crença em um sistema poderia estar em oposição a uma crença incompatível em outro. ${ }^{11}$

No caso moral é fácil ver esse problema. Existem diversas teorias morais que conhecemos pela história da filosofia, por exemplo, a ética das virtudes, o kantismo ou ética deontológica, o consequencialismo, o contratualismo etc. Todas essas concepções morais são coerentes internamente, mas, quando aplicadas em situações específicas, podem ser percebidas como incompatíveis entre si. Por exemplo, se quero saber se é correto ou não mentir para salvar a vida de um inocente, eu terei uma resposta diferente se tomar como referência o consequencialismo ou a ética kantiana. A resposta será afirmativa se eu usar a teoria consequencialista como padrão, mas será negativa se eu fizer uso de um modelo deontológico kantiano. Mas, então, como escolher entre essas duas teorias levando em consideração apenas o critério de coerência? Vejamos outra situação similar. Queremos saber se devemos agir de forma solidária ou mesmo de forma caridosa em relação aos sem-teto, a ponto de pensar a respeito de nossa obrigação em destinar o valor de dez por cento de nossa renda para esse auxílio. Se tomarmos a ética das virtudes como padrão, parece que teríamos uma obrigação perfeita em sermos solidários, lembrando que a virtude é uma disposição interna do agente que implica querer saber como se deve viver. Mas, alternativamente, se usarmos o contratualismo como teoria moral de base, parece que nossa obrigação à solidariedade/caridade seria apenas imperfeita, o que não geraria direitos. Mas o problema parece ser: ou essa escolha se basearia em algum critério que vai além da coerência ou ela parece ser arbitrária, sendo que ambas as alternativas evidenciariam um problema para a coerência ser estipulada como suficiente para a justificação de uma crença.

A terceira e última objeção a que faremos referência é a da circularidade viciosa. Essa crítica postula que existiria uma circularidade entre determinadas crenças que seriam tomadas como práticas e os princípios. Se perguntarmos

11 Robert Audi faz essa crítica ao coerentismo a respeito dos múltiplos sistemas coerentes de crenças que são mutuamente incompatíveis. Para Audi, o problema está em identificar que, se a coerência for a única fonte de justificação, não ficaria claro como a percepção, memória ou introspecção contribuiriam para a justificação. Audi também aponta que um grande problema para o coerentismo é explicar qual é o papel da experiência e da razão como fonte de justificação. Ver: Audi, 2003, pp. 199-201. 
como os princípios são justificados, teríamos que olhar para as crenças que são assumidas. Mas, alternativamente, se perguntarmos como podemos encontrar um critério para a justificação dessas crenças ponderadas, então, teríamos que apontar para os princípios morais. Essa objeção conhecida como a da circularidade viciosa parece-nos a mais vigorosa crítica feita ao coerentismo, uma vez que haveria uma estrutura circular para a justificação e que essa estrutura seria viciosa por não apresentar nenhum outro critério além dos anteriormente mencionados, a saber, crenças ponderadas e princípios em um certo nível de generalidade.

Essa crítica de circularidade viciosa é feita de forma emblemática por Harvey Siegel ao analisar o alcance justificacional do método do equilíbrio reflexivo, como utilizado por Nelson Goodman em "Fact, Fiction, and Forecast". O problema identificado é que os princípios inferenciais seriam justificados na medida em que eles se harmonizassem com nossas práticas inferenciais. De outro lado, uma prática inferencial seria justificada na medida em que ela se harmonizasse com nossos princípios inferenciais, havendo uma acomodação mútua entre juízos e princípios (Goodman, 1983, p. 64). O problema apontado por Siegel é que essa circularidade não seria virtuosa, assim como pretendida por Goodman, mas, antes, seria viciosa, uma vez que não ofereceria nenhum outro elemento além daqueles que se justificariam intersubjetivamente. É por isso que, no seu entender, o método do equilíbrio reflexivo falha como uma concepção plausível de justificação dos nossos juízos concernentes com esses princípios inferenciais. ${ }^{12}$

\section{IV}

Nestas últimas seções do texto, tentaremos esboçar respostas a essas três objeções feitas ao coerentismo moral holístico, procurando apontar tanto para as suas vantagens como para os seus limites. Iniciamos respondendo à primeira objeção endereçada ao coerentismo, a saber, a objeção ao isolamento, que tem como foco central o questionamento a respeito da credibilidade inicial dada

12 O problema central do coerentismo que está sendo apontado por Siegel é que a justificação coerentista se basearia na ideia de credibilidade e, assim, uma crença estaria justificada pela credibilidade que se poderia atribuir ao sistema como um todo. A crítica endereçada é que nossa medida de credibilidade não pode ser apenas uma questão de nossa confiança do que tomamos por estar justificado. Como podemos estar enganados sobre os nossos juízos de que algo está justificado ou é credível, nossa confiança pode ser um erro. A falácia do jogador (gambler's fallacy) mostra que podemos estar errados em nossos juízos, como é o caso dos juízos probabilísticos que se fazem em certos jogos de azar, tal como no jogo de roleta, quando se vai contra a probabilidade de cinquenta por cento cair a cor vermelha ou preta em cada lance. Ver: Siegel, 1992, pp. 43-44. 
aos juízos morais ponderados, que serviriam de base para o desenvolvimento de teorias morais. Pensamos que uma forma interessante de responder a essa crítica seja apontando para o importante papel do reconhecimento social para a justificação no modelo holístico de teoria moral, de forma a levar em consideração um elemento coletivo para a validação desses juízos ponderados. Em outras palavras, faremos uso de um holismo social que estará pressuposto no coerentismo moral.

Iniciamos fazendo referência ao argumento central de um holismo social tal como defendido por Philip Pettit em "The Common Mind" e por Michael Esfeld em "Holism and analytic philosophy". O holismo aqui é tomado como social e compreendido a partir de um sistema de crenças, de forma que uma crença ou regra será justificada ou aprovada se ela for coerente com um sistema integrado de crenças, sendo que esse sistema integrado de crenças é pertencente a uma dada comunidade social. Isso já antecipa a resposta de que a justificação da crença ou regra se dará em um âmbito de convergência social.

Esfeld apresenta uma fórmula de um sistema holístico que é bastante esclarecedora, uma vez que ressalta as características de dependência ontológica genérica das partes do sistema e, também, que essas partes instanciam certas famílias de propriedades. Vejamos:

Considere um sistema de tipo $S$ e suas partes constituintes. Para cada constituinte de $S$, existe uma família de propriedades qualitativas que faz algo uma parte constituinte de um $S$ em caso de existir um arranjo adequado. Um $S$ é holístico se e somente se a seguinte condição for satisfeita por todas as coisas que são seus constituintes: com respeito a instanciação de algumas das propriedades que pertencem a tal família de propriedades, uma coisa é ontologicamente dependente de uma forma genérica se realmente existir em outras coisas em conjunto com as quais é arranjada de tal forma que exista um $S$ (Esfeld, 1998, p. 375).

Assim, a condição necessária para algo ser parte do sistema é ter todas ou quase todas as propriedades que pertencem a tal família de propriedades e a condição suficiente é o arranjo adequado da parte no sistema. É importante ressaltar que Esfeld está pensando em um sistema holístico como um sistema de crenças dentro de uma comunidade social, de forma a estipular que uma crença $p$, por exemplo, terá certas propriedades, tais como significado e conteúdo conceitual, sendo confirmada ou não, justificada ou não apenas se existir outras crenças em conjunto constituindo um sistema de crenças que é coerente. Ele está falando de um holismo social, uma vez que compreende o seguir uma regra como circunscrito às relações sociais (Esfeld, 1998, p. 366).

Essa dimensão social de um sistema holístico também é ressaltada por Pettit. A primeira premissa defendida por ele é a de que seguir regras é um 
empreendimento de relação interpessoal, o que trará por resultado uma tese interativa. Essa premissa se conectará com a segunda que afirma que as regras do pensamento humano são comuns, sendo regras que outros podem afirmar como uma posse comum. Vejamos o argumento apresentado:

1. Um ser humano pode seguir uma regra apenas sob uma base de interação interpessoal ou intertemporal.

2. As regras seguidas por um ser humano que pensa são comuns. Elas são regras que outros podem afirmar como uma posse comum.

3. Se um ser humano segue uma regra apenas sob a base de uma interação intertemporal consigo mesmo, então esta regra não é comum.

Conclusão: As regras seguidas por um ser humano pensante não são seguidas sob a base de tal interação intrapessoal apenas; elas devem ser seguidas sob uma base envolvendo interação com os outros (Pettit, 1993, pp. 180-181).

Pettit está defendendo, acertadamente em nosso entender, que uma concepção holística não implicará nenhuma forma de relativismo, uma vez que se baseará em uma concepção de sistemas de pensamento comum, de forma a identificar que a capacidade de pensamento dos agentes requer o estabelecimento de uma comunidade com os outros. Isso significa dizer que o processo de pensamento é visto como um processo de seguir uma regra, o que implicará ver o pensamento como um empreendimento cooperativo. Aqui está a chave para se entender o ponto central do argumento: seguir uma regra é uma ação eminentemente social e pensar é um processo de seguir regras; logo, pensar é um ato eminentemente social, o que parece exigir uma convergência intersubjetiva em algum nível para se obter a justificação da crença. ${ }^{13}$

De posse disso, podemos apontar quais as razões que teríamos para creditar maior credibilidade inicial a essas crenças morais ponderadas, tais como as que afirmam que "a discriminação racial é injusta" ou que "devemos levar em consideração o sofrimento alheio": elas compartilhariam uma propriedade qualitativa comum a um sistema coerente de crenças, o liberal, por exemplo, que conta com princípios que defendem a igualdade, liberdade e dignidade da pessoa, bem como com crenças factuais que demonstram que a discriminação racial é ineficiente do ponto de vista econômico e que seres sencientes sentem dor e procuram evitá-la sempre que possível.

13 Este requisito social do pensamento não é de tipo causal, mas é de uma dependência superveniente que se dá pela condição de publicidade. É por isso que, para Pettit, apenas existe uma regra que se está tentando seguir se existir uma convergência negociável nas nossas respostas (negociable convergence). Ver: Pettit, 1993, pp. 177-188. 
A crítica central endereçada ao coerentismo era a de que crenças factuais seriam justificadas na ausência de qualquer dado empírico e, dessa forma, a justificação se basearia numa relação acidental com o mundo, sendo que, no caso moral, as crenças poderiam apenas refletir nossos próprios preconceitos, tendo uma conexão apenas com o mundo interno do agente. Será esse o caso? Veja-se que a crença que diz que "a discriminação racial é injusta" pode ser justificada ao se mostrar a sua coerência a um sistema coerente de crenças, como o liberal, sistema esse formado por crenças e princípios morais e crenças factuais que procuram descrever o mundo objetivamente. O ponto central aqui seria reconhecer que há crenças factuais dentro desse sistema coerente, por exemplo, que identifica a ineficiência econômica da discriminação racial e a igualdade genética dos seres humanos independentemente de sua etnia, e que essas crenças factuais possuem uma ampla aceitação. É claro que alguém poderia objetar e dizer: Então, o que garantiria a justificação da crença moral não seria a verdade da crença factual?

O coerentista não precisa admitir isso. Ele poderia contra-argumentar e dizer que o que justifica a crença moral não é a verdade da crença factual, mas a existência de uma concordância intersubjetiva a respeito dessas crenças tanto morais como não morais, uma vez que o conhecimento é um empreendimento cooperativo e não um processo que se daria de forma isolada pelos agentes. E, estando a crença justificada para um agente moral, ela poderia ser tomada como uma razão para a sua ação. Por exemplo, estando justificada a crença que diz que "a discriminação racial é injusta" para um certo agente, essa crença poderia ser tomada como um fato para condenar as práticas de escravidão. Parece importante levar em consideração que sempre estamos justificando uma crença moral no interior mesmo de uma comunidade moral e, assim, a objetividade da esfera moral não seria garantida por nenhum tipo de referência puramente externa ao mundo humano. ${ }^{14}$ É claro que isso ainda não responde ao problema de se uma teoria moral, que é um sistema coerente de crenças, poderia não ter nenhuma relação com o mundo externo. Mas deixaremos para enfrentar essa questão ao tentar responder à segunda objeção.

Atualizando a formulação da justificação moral coerentista apresentada anteriormente, de maneira a incluir essa resposta à primeira objeção, teríamos

14 Em direção similar, John Searle faz uma distinção interessante entre fatos brutos e fatos institucionais. Os primeiros seriam fatos do tipo que o Monte Everest tem neve e gelo próximo ao seu cume ou que átomos de hidrogênio têm um elétron. São fatos totalmente independentes das opiniões humanas. Em contraste com os fatos brutos, os fatos institucionais são inteiramente dependentes do acordo humano, tais como o são o dinheiro, a propriedade, o governo e o casamento. Sobre a construção da realidade social, ver: Searle, 1995, pp. 1-4. 
que uma crença moral $p$ estará justificada para um agente $S$ em um tempo $t$ e em circunstâncias $C$ se e somente se ela for coerente com um sistema consistente de crenças $C S$, sistema caracterizado pela convergência intersubjetiva e, assim, $p$ poderá contar como um fato $F$ para $S$ fazer uma ação $A$.

\section{V}

O próximo passo será procurar responder à objeção dos sistemas coerentes alternativos, objeção que questiona a respeito do critério que seria usado pelo agente para escolher entre sistemas de crenças consistentes que são diferentes e até mesmo contraditórios entre si. Vejamos que, no caso moral, o problema se daria pela existência de várias teorias que são consistentes, por exemplo, o consequencialismo, a deontologia, a ética das virtudes etc., que dão respostas bastante diferentes às situações dilemáticas, como no caso de o agente se perguntar pelo seu dever de auxiliar aos sem-teto. Seria esse dever perfeito ou imperfeito? O problema parece ficar ainda mais dramático se observarmos que o mesmo agente poderia possuir dois sistemas coerentes de crenças em tempos diferentes, de forma a cada crença em um sistema poder estar em oposição a uma crença em outro. Imaginemos alguém que sempre adotou o modelo consequencialista de raciocínio moral até uma certa altura da vida e depois teve como que uma espécie de conversão ao kantismo. Não seriam todas as crenças desses dois sistemas incompatíveis ente si, ou quase todas? Isso não nos apontaria para um limite em tomar o critério de coerência como sendo suficiente para a justificação da crença moral?

Pensamos que uma forma inicial de resposta a essa objeção seria identificar que a escolha de um sistema tem uma relação direta com a função que o sistema cumpre. No caso de uma teoria moral, qual seria a sua função? É claro que não há uma resposta unânime a essa pergunta, mas, de forma geral, poderíamos dizer que uma teoria moral teria a função de nos mostrar como nós deveríamos agir em certos casos ou que tipo de pessoa nós deveríamos ser, quer dizer, ela teria o papel de auxiliar-nos em enfrentar problemas específicos, apresentando um certo tipo de raciocínio, por exemplo, para auxiliar a nossa escolha. Nosso ponto inicial é chamar a atenção de que a tese da funcionalidade da teoria moral será usada para tentar identificar como se daria a escolha entre sistemas alternativos.

Dito isso, podemos iniciar apontando para o critério de consistência para a escolha dos diferentes sistemas coerentes. O sistema de crenças mais consistente deve ser escolhido em contraposição a outro sistema menos consistente. Com isso, parece que já conseguiríamos excluir algumas 
teorias que não apresentam consistência lógica entre as suas crenças ou que poderíamos identificar, talvez, uma mais baixa consistência. Um exemplo de uma teoria com mais baixa consistência poderia ser um certo tipo de marxismo revolucionário que defenderia "a moralidade do assassinato" a partir de premissas que defendem "a igualdade de todas as pessoas". É claro que a crença na "necessidade da mudança estrutural" e na "luta de classes" poderia fundamentar a dedução da defesa da "moralidade do assassinato", mas não seria consistente com a crença na "igualdade de todas as pessoas" que faz parte desse mesmo sistema. De forma similar, talvez já pudéssemos excluir algumas teorias de cunho relativista, mostrando, por exemplo, que a existência de diferentes costumes sociais não implicaria necessariamente a existência de diferentes valores morais, de forma que mostrar os hábitos de infanticídio na Grécia antiga ou entre os esquimós não provaria que esses povos não valorizam a vida e segurança de seus filhos e demais familiares. Mas, é claro, isso não nos auxiliará na escolha entre as teorias que são consistentes, mas antagônicas em muitos aspectos. ${ }^{15}$

Uma conhecida estratégia para identificar as razões de escolha entre teorias morais consistentes é tentar apontar para a teoria que seria verdadeira, no sentido em que as suas crenças corresponderiam a uma propriedade moral como a "correção" ou o "erro". O problema dessa estratégia fundacionista é que ela parece não se harmonizar a uma sociedade contemporânea com diversidade moral. Apontar para a verdade de uma teoria moral teria por implicação ter de reconhecer a falsidade de algumas outras. Isso não seria dogmático? E mais, isso não estabeleceria uma assimetria entre as crenças morais dos agentes e os critérios normativos que seriam correspondentes aos fatos morais? Em contrapartida, uma estratégia coerentista moral não precisa fazer uso do critério da verdade, necessariamente, para tentar identificar as razões de escolha entre as teorias morais igualmente consistentes. Ela pode, por exemplo, perguntar se alguma dessas teorias seria mais aceitável para os agentes morais e o que poderia caracterizar adequadamente as condições dessa aceitabilidade. Vejamos um exemplo disso. Como escolher entre o liberalismo e o nazismo sem tentar identificar qual dessas teorias seria a verdadeira?

15 Parece que um niilismo de tipo nietzschiano também já poderia ser excluído por inconsistência, uma vez que a conclusão da não existência de valores morais objetivos não seguiria das premissas que apontam uma historicidade dos valores morais. Não é porque povos diferentes em épocas diversas atribuem diferentes valores morais que não poderiam existir valores morais absolutos ainda não conhecidos por esses povos. Ou não é porque existe diversidade moral que isso necessariamente implicaria subjetivismo, pois poderia ser o caso de termos diversidade moral e objetividade, como é o caso defendido pelas éticas neocontratualistas ao fazer uso do procedimentalismo. Sobre o relativismo moral, ver: Blackburn, 2000, pp. 38-48. 
Poder-se-ia perguntar aos agentes morais qual teoria seria a mais aceitável. A resposta, provavelmente, diria que o liberalismo seria mais aceitável para os envolvidos, isto é, para nós que vivemos em sociedades contemporâneas com pluralismo moral. Mas por que seria mais aceitável? Talvez pela razão de o liberalismo ser mais razoável do que o nazismo, considerando o senso moral de comunidades políticas democráticas contemporâneas. Veja-se que um liberalismo igualitário, por exemplo, defende os princípios de liberdade, igualdade e bem comum, e esses princípios morais parecem estar em sintonia com os juízos morais dos cidadãos de sociedades contemporâneas que valoram positivamente a liberdade, a dignidade e a igualdade das pessoas. No caso do nazismo, parece que esses valores professados pelos agentes não estariam sintonizados com o princípio da discriminação racial, por exemplo, provavelmente implicando a rejeição a esse sistema. Mas o que se entenderia por razoabilidade aqui? Inicialmente, podemos explicar esse critério da seguinte maneira: a razoabilidade de um sistema implicará um conjunto de crenças que não poderiam ser rejeitadas ou derrotadas por um sistema alternativo de crença. Mas vejamos como podemos explicar o conceito de razoabilidade de uma forma mais detalhada. Para tal fim, faremos uso da concepção coerentista de Lehrer e do neocontratualismo de Scanlon.

Tomando como referência o coerentismo defendido por Keith Lehrer, temos que uma pessoa estaria justificada em aceitar uma proposição ou crença apenas no caso de tal proposição ou crença ser coerente com a parte relevante de seu sistema cognitivo. Dessa forma, o que possibilitaria a justificação seria a aceitação que se dá ao sistema, o que é o mesmo que dizer que a justificação se daria por coerência entre a crença ou a proposição com o sistema do qual a crença ou a proposição fazem parte. Assim, uma crença é justificada apenas se ela for mais razoável que as crenças alternativas em termos de um sistema de crenças de fundo, ou que as crenças alternativas possam ser neutralizadas em termos desse sistema. Em suas palavras:

$S$ está pessoalmente justificado em aceitar que $p$ em $t$ se e somente se $S$ está justificado em aceitar que $p$ sobre a base de aceitação do sistema de $S$ em $t$. E, assim, $S$ sabe que $p$ em $t$ se e somente se $S$ está justificado em aceitar $p$ em $t$ de uma forma que $p$ não seja derrotada (undefeated) (Lehrer, 1988, pp. 129-131).

O ponto central do argumento de Lehrer é vincular a aceitabilidade da crença com a sua razoabilidade e essa com a condição de essa crença não poder ser derrotada. Em outras palavras, podemos entender que a escolha seria dada pela aceitabilidade das crenças do sistema, o que significaria reconhecer quais crenças são mais razoáveis para o agente, sendo que a razoabilidade 
de um conjunto de crenças implicaria que elas não seriam derrotadas pelas crenças de um sistema alternativo. Importante notar que estamos falando do que faria um agente estar pessoalmente justificado em aceitar uma certa crença que $p$ e não do que apenas justificaria uma crença $p$ de um ponto de vista intersubjetivo. ${ }^{16}$

Outra maneira de apontar para a força do critério de razoabilidade é ver qual papel ele desempenha no interior de uma teoria moral. Tomando o neocontratualismo de Scanlon como referência, o que faz uma ação ser tomada como errada é que ela não seria aprovada por algum princípio que possuiria a característica de não poder ser razoavelmente rejeitado. Vejase que a importância do critério de razoabilidade é distinguir entre o que é aceitável para todos os envolvidos e o que é inaceitável. Isso quer dizer que os princípios morais seriam válidos quando passam no teste da não rejeitabilidade, isto é, quando não são rejeitados razoavelmente pelos outros. Princípios de ajuda mútua, fidelidade à promessa e liberdade de expressão passariam no teste da não rejeitabilidade porque são razoáveis dada a cultura pública das sociedades contemporâneas. Parece que esse não seria o caso com o princípio da discriminação racial como adotado pelo nazismo, ou mesmo com um princípio que requeresse estrita neutralidade entre amigos e estranhos, uma vez que eles seriam incompatíveis com as atitudes e valores da igualdade e amizade, atitudes e valores que são prezados socialmente. ${ }^{17}$

Mas como entender mesmo o critério de razoabilidade para os nossos propósitos específicos? A partir do que vimos, podemos entender a razoabilidade tanto como um critério epistemológico quanto moral, isto é, como uma capacidade do sujeito em reconhecer qual crença passaria no teste de não ser derrotada, bem como uma capacidade do agente em dar um peso apropriado às reivindicações morais das pessoas. Com isso, estamos entendendo a razoabilidade como uma virtude tanto intelectual quanto moral e como uma condição necessária para a justificação. ${ }^{18}$

16 Lehrer define uma justificação pessoal da seguinte maneira: " $p$ é coerente com o sistema aceito de $S$ em $t$ se e somente se é mais razoável para $S$ aceitar $p$ que aceitar qualquer outra reivindicação alternativa sobre a base do sistema aceito de $S$ em $t$ ". E, "S está pessoalmente justificado em aceitar que $p$ em $t$ se e somente se $p$ derrota tudo que compete com $p$ sob a base do sistema aceito de $S$ em $p$ " (Lehrer, 1990, pp. 117 e 118).

17 Scanlon formula de seguinte maneira o seu critério moral contratualista: "[...] pensar sobre o certo e errado é, no seu nível mais básico, pensar sobre o que seria justificado aos outros sobre os fundamentos que eles, se motivados de forma apropriada, não rejeitariam razoavelmente" (Scanlon, 1998, p. 5).

18 Essa também é a maneira que John Rawls compreende a razoabilidade, isto é como uma virtude moral e intelectual, uma vez que ela é uma "disposição do agente em propor e cumprir os termos da cooperação, bem como é uma disposição para reconhecer os limites da razão e do juízo e aceitar as suas consequências no uso público da razão para determinar a legitimidade do poder político" (Rawls, 1996, p. 54). 
Atualizando a formulação do que contaria como uma crença justificada nesse modelo coerentista de forma a tentar responder a essa segunda objeção, teríamos que $p$ estará justificada para $S$ em $t$ e $C$ se $p$ for coerente com $C S$, sistema caracterizado pela convergência intersubjetiva e razoabilidade e, assim, $p$ poderá contar como um $F$ para $S$ fazer $A$.

Mas notemos que isso não é tão simples como poderíamos supor, ao pensar que a coerência dada pelo critério de razoabilidade nos apontaria claramente para um dos sistemas coerentes alternativos como o vencedor. Como decidir no caso de nos depararmos com dois sistemas de crenças que são consistentes e sua coerência dada pela razoabilidade em ambos os casos? Vejamos um exemplo dessa situação, recorrendo novamente ao caso dos dois amigos, agora em uma nova discussão. Augusto acredita que o aborto é imoral e isto em razão de ele acreditar que não devemos matar seres humanos inocentes e, também, que a vida possui um caráter sagrado, absoluto. Por sua vez, Beto acredita na moralidade do aborto e isto em consequência de sua crença em que devemos respeitar a autonomia dos indivíduos e, também, que a vida possui apenas um valor sensível, relativo. Agora, imaginemos que Augusto e Beto estejam discutindo sobre a questão da descriminalização do aborto e ambos apresentassem as suas razões para defenderem as suas crenças antagônicas. Ninguém poderá apontar para uma contradição na argumentação e isso porque tanto Augusto como Beto poderão perceber uma consistência do argumento utilizado pelo outro em razão da harmonização entre a crença moral, o princípio moral e a crença não moral. Também, poderão aceitar que as crenças apresentadas consistentemente são razoáveis, além de possuírem convergência intersubjetiva. Quais as alternativas restantes, então? Uma primeira possibilidade parece ser a de Augusto ou Beto modificarem os seus juízos morais ponderados por identificarem uma maior consistência no argumento do outro. Isso parece difícil nesse caso específico, uma vez que a real divergência não parece recair sobre os princípios morais defendidos, mas sobre as crenças não morais de vida sagrada em contraposição à vida sensível. A não ser que haja uma conversão de uma posição religiosa para laica ou vice-versa, não parece que seria o caso de um deles mudar suas convicções morais. A segunda possibilidade, então, poderia ser a de ambos assumirem uma posição de suspensão do juízo. A terceira poderia ser a de aceitar um pluralismo moral sobre a questão. Estas duas últimas alternativas parecem mais plausíveis nesse caso, uma vez que não haveria evidências suficientes para a confirmação das crenças não morais assumidas pelos envolvidos. Nessa circunstância, por exemplo, pensamos que Augusto estaria justificado em recusar a moralidade do aborto e não o praticar em situações particulares, mas 
não teria legitimação para defender a sua criminalização, uma vez que pôde reconhecer a coerência do argumento de Beto. Mesmo que isso não seja razão para ele mudar a sua crença moral, poderia ser suficiente para aceitar como legítima uma crença moral diferente. ${ }^{19}$

O que o método do equilíbrio reflexivo parece mostrar é que a justificação de crenças morais não precisa ser vista como um processo de encontrar a correspondência para certos fatos morais absolutos, o que implicaria dualismo, dogmatismo e, sobretudo, assimetria entre os juízos morais e esses mesmos fatos. Como não há o uso de fatos morais para a justificação e nem se faz uso da noção de correspondência, a justificação oportunizada pelo equilíbrio reflexivo se daria por um processo de reciprocidade entre os princípios e as crenças morais e não morais. $\mathrm{O}$ processo não quer mostrar a verdade da regra em primeiro lugar para saber qual será a resposta dada ao caso em questão. Antes, a regra poderia ser estipulada a partir de sua convergência com crenças morais e não morais. Isso parece significar que o equilíbrio reflexivo possibilitaria uma pluridirecionalidade entre as regras e os casos, o que implicaria uma posição de simetria entre os juízos ponderados, os princípios morais e as crenças genéricas, oportunizando uma saudável e desejada superação da dicotomia entre os fatos e os valores. É claro que ele não parece suficiente para determinar como escolher entre sistemas consistentes razoáveis, mas parece possibilitar, ao menos, um procedimento para orientar a discussão moral de forma mais racional possível. ${ }^{20}$

\section{VI}

A última objeção que tentaremos responder é a de se a justificação coerentista não implicaria uma circularidade viciosa. A acusação feita ao coerentismo moral é que sua forma de justificação recairia em uma

19 Esse exemplo segue a interpretação de Scanlon a respeito do equilíbrio reflexivo, que seria um método que um indivíduo deveria usar para decidir o que pensar sobre uma questão moral específica. Assim, os juízos ponderados poderiam ser considerados como crenças que serviriam como razões para uma dada ação, isto é, seriam tomados como fatos que obrigariam a uma certa ação. O ponto central de Scanlon é chamar a atenção que não bastaria assegurar com confiança um juízo ponderado, pois ele deveria parecer claramente verdadeiro sob condições corretas de pensamento. Além disso, também seria apropriado tratar dessas crenças como juízos ponderados em um processo de equilíbrio reflexivo se não tivermos uma razão aparente para duvidar delas. O pequeno truque seria tratar o juízo ponderado como provisoriamente verdadeiro. A esse respeito, ver: Scanlon, 2014, pp. 82-83.

20 Creio que a força desse método interpretado de maneira coerentista esteja em sua defesa da superação de uma forte dicotomia que é bem conhecida na filosofia moral, que é a dicotomia entre fatos e valores, seja no modelo platônico, seja em uma concepção positivista, por exemplo. O equilíbrio reflexivo parece pressupor uma relação de certo tipo entre essas duas diferentes esferas. Sobre a história da dicotomia entre fatos e valores e seu colapso, ver: Putnam, 2004, pp. 7-45. 
circularidade viciosa, uma vez que só haveria crenças ponderadas tomadas como práticas e princípios morais nesse processo justificatório, não existindo nada além disso. Essa crítica tem quase sempre o equilíbrio reflexivo como seu alvo predileto. O problema específico aponta que uma crença moral, tal como a que afirma que "a tolerância religiosa é boa", estaria justificada por sua credibilidade do sistema como um todo, por exemplo, o sistema liberal e, assim, a justificação teria por base a confiança do que tomamos como justificado. Vejamos que a crítica ressalta que a nossa medida de credibilidade não poderia ser apenas uma questão de nossa confiança do que tomamos por estar justificado, uma vez que podemos estar enganados sobre os nossos juízos que algo está justificado ou é credível. Por exemplo, poderíamos estar enganados a respeito de nossa razoabilidade ou mesmo racionalidade e, assim, nossa confiança em um sistema razoável poderia ser um erro que colocaria em risco a credibilidade atribuída às nossas crenças morais ponderadas.

Em primeiro lugar, seria importante apontar que a circularidade pode ser tomada como boa no caso moral em razão de ela possibilitar a superação da dicotomia radical entre fatos empíricos e valores morais, ou entre crenças e princípios morais ou mesmo virtudes. No momento que a justificação se daria pela coerência da crença ao sistema consistente de crenças, que possui crenças morais, princípios morais e crenças empíricas, parece não haver uma reivindicação de uma barreira intransponível entre as esferas factual e normativa, pois as crenças factuais teriam um papel relevante para a justificação de crenças morais. Mas não seria essa circularidade viciosa e isso não colocaria em risco toda a justificação? Pensamos que não, e isso em razão de tomarmos o conhecimento moral objetivo a partir de um entendimento social e não a partir de um processo inferencial entre crenças básicas e não básicas. Por exemplo, a aprovação histórica e social teria um papel relevante para a identificação da razoabilidade de certas convicções morais ou critérios normativos.

Mas isso não responderia à crítica de circularidade, pois mesmo sendo virtuoso o círculo, ainda haveria a circularidade como problema epistemológico. Outra forma de tentar responder a essa objeção seria buscar identificar se haveria algum elemento externo ao sistema coerente de crenças que poderia servir de critério para confirmar a justificação de tipo coerentista. Retomemos o argumento da funcionalidade da teoria, observando que a escolha de um sistema parece ter uma relação direta com a função que o sistema cumpre. Iniciamos apontando que um dos papéis que parecem relevantes em uma teoria moral seja o de dizer como deveríamos agir ou mesmo como deveríamos ser com o objetivo de procurar resolver nossos problemas de convivência social. 
Para uma teoria moral poder cumprir com esse papel parece necessário, então, que os agentes da comunidade agissem de fato segundo os critérios normativos propostos pela teoria e isso parece trazer por consequência a garantiria da estabilidade social, uma vez que teríamos agentes agindo moralmente de forma efetiva. Essa estabilidade seria dada internamente e não externamente, o que implicaria ver a estabilidade alcançada pela motivação apropriada dos agentes e não por algum tipo de coerção. Quer dizer, estamos falando de uma estabilidade pelas razões corretas.

Com isso posto, podemos argumentar que, dado que uma teoria moral teria o papel de oportunizar a estabilidade social, a teoria que melhor cumprir com essa função deveria ser a escolhida. Por exemplo, se devemos escolher entre um liberalismo igualitário que pode ser identificado na justiça como equidade rawlsiana e o utilitarismo e olharmos para a funcionalidade da teoria, a escolha pela justiça como equidade não parecerá arbitrária, uma vez que seus princípios de igual liberdade, igualdade equitativa de oportunidades e diferença parecem melhor se harmonizarem com as crenças morais dos cidadãos de democracias liberais contemporâneas a respeito da igualdade e liberdade das pessoas, bem como a respeito do papel primordial do bem comum. Adotar o liberalismo igualitário parece trazer por consequência ter uma sociedade mais estável do que adotando um modelo moral alternativo, como o utilitarista, em que o princípio do sacrifício seria efetivo nas relações entre os indivíduos. A questão relevante aqui é chamar a atenção para a dificuldade que pessoas como nós teríamos em agir conforme o princípio da utilidade em todas as dimensões de nossa vida social, uma vez que nossas crenças morais ponderadas não aprovariam alguns de seus efeitos sociais excludentes e isso poderia abalar a estabilidade no interior mesmo da comunidade.

Isso quer dizer que um princípio moral seria aprovado por sua função de garantia de estabilidade social e não apenas por sua coerência interna com uma crença moral. Por exemplo, o princípio da liberdade seria aprovado por garantir mais estabilidade social do que o princípio da utilidade e não apenas em razão de sua coerência com a crença na tolerância religiosa. Isso parece implicar que a escolha por um princípio dentro de um sistema moral não se daria apenas por sua convergência intersubjetiva e razoabilidade, mas, também, pela possibilidade de garantir a estabilidade desejada. Importante frisar que a revisibilidade dos juízos ponderados e princípios morais é uma marca fundamental do coerentismo holístico. Assim, um princípio seria justificado por uma prática, da mesma forma que juízos morais seriam justificados por sua coerência com princípios que seriam justificados por uma prática. E o que faria uma prática ser justificada? A possibilidade de garantir a estabilidade 
social. E isso parece querer dizer que determinadas crenças morais possuiriam uma credibilidade maior em razão de sua função, o que poderia ser explicado pela confiança no sistema inteiro do qual a crença faz parte em conseguir cumprir a sua função de possibilitar a estabilidade social.

Atualizando a nossa formulação a fim de incluir a nossa resposta à objeção de circularidade, teríamos que $p$ estará justificada para $S$ em $t$ e $C$ se ela for coerente com $S C$, sistema caracterizado pela convergência intersubjetiva, razoabilidade e que garante estabilidade social correta e, assim, $p$ poderá contar como um $F$ para $S$ fazer $A$.

Mas alguém poderia perguntar: Por que a estabilidade social seria desejável? Não seria esse desejo explicado pelas nossas próprias características de razoabilidade e racionalidade? Não nos encontraríamos aqui novamente em uma situação circular, em que princípios seriam escolhidos por garantirem aquilo a que nós próprios já creditamos grande confiança? Temos que reconhecer que sim, uma vez que parece ser a nossa confiança em nossa própria racionalidade e razoabilidade que explicaria a desejabilidade da estabilidade. Parece que nos encontramos novamente com um sistema circular para a justificação. Entretanto, é possível que essa circularidade possa ser tomada com virtuosa e não viciosa, uma vez que as crenças podem ser sempre revisáveis a partir de sua função específica nesse caso moral. A revisibilidade das crenças nesse modelo tem um importante papel em garantir que não justifiquemos sempre os nossos próprios preconceitos.

Com isso dito, podemos refletir que uma concepção moral coerentista de tipo holístico é inegavelmente circular, mas isso não significaria, necessariamente, tomar essa circularidade como um irremediável problema epistêmico quando olhamos especificamente para o âmbito da moralidade. Dado que estamos sempre inseridos em uma dada comunidade moral quando pensamos na justificação de critérios normativos, a coerência pode e deve ser vista como uma virtude, ao menos para aqueles que não querem cair novamente nos problemas relacionados ao fundacionismo, tais como dogmatismo, dualismo e assimetria, problemas que estariam presentes em uma concepção tradicional de intuicionismo moral, por exemplo, e estão empenhados na defesa de um modelo moral que aposta na pluridirecionalidade entre a regra e o caso para a justificação das crenças morais.

Entretanto, poderia ser o caso de ser preferível adotar uma posição híbrida entre fundacionismo e coerentismo, como o funderentismo (foundherentism) proposto por Susan Haack, por exemplo, considerando que a coerência do sistema seria parte integrante para a justificação, mas que isso não impediria de se tomar certas crenças como justificadas a partir de suas evidências empíricas 
ou a partir da experiência. Dito de outra forma, a justificação não seria apenas unidirecional, mas envolveria relações permanentes de apoio mútuo entre as crenças. ${ }^{21}$ Com esse modelo, cremos que conseguiríamos resolver o problema da circularidade de uma forma mais eficiente, sem, entretanto, ter de abandonar o relevante papel da coerência para a justificação de crenças morais. O problema seria tentar precisar o que contaria mesmo como experiência em se tratando de crenças morais e não de crenças empíricas. Infelizmente, não poderemos realizar essa investigação aqui, pois isso ultrapassaria e muito os propósitos deste artigo que teve apenas por objetivo central procurar ressaltar as virtudes do coerentismo para o âmbito moral a partir do enfrentamento com as suas mais conhecidas objeções.

\section{Referências}

AUDI, R. "Epistemology: a contemporary introduction to the theory of knowledge". 2a ed. London: Routledge, 2003.

BÍBLIA. A.T. "Bíblia Sagrada". Versão de Antonio Pereira de Figueiredo. São Paulo: Ave Maria, 1980.

BLACKBURN, S. "Relativism". In: H. Lafollete (org.). The Blackwell Guide to Ethical Theory. Oxford: Blackwell, 2000. pp. 38-52.

BONJOUR, L. "The Structure of Empirical Knowledge". Cambridge, MA: Harvard University Press, 1985.

. "A version of internalist foundationalism". In: L. Bonjour; E. Sosa. Epistemic

Justification: Internalism vs. Externalism, Foundations vs. Virtues. Oxford: Blackwell, 2008. pp. 5-96.

BRANDT, R. "A Theory of the Good and Right". Oxford: Clarendon Press, 1979.

."The science of man and wide reflective equilibrium". Ethics, Vol. 100, Nr.

2, pp. 259-278, 1990.

BRASIL. "Constituição da República Federativa do Brasil". Brasília: Senado Federal, Centro Gráfico, 1988.

DANCY, J. "Ethics without Principles". Oxford: Oxford University Press, 2004.

DANIELS, N. "Wide reflective equilibrium and theory acceptance in ethics". The Journal of Philosophy, Vol. 76, Nr. 5, pp. 256-282, 1979.

ESFELD, M. "Holism and analytic philosophy". Mind, New Series, Vol. 107, Nr. 426, pp. 365-380, 1998.

GOODMAN, N. "Fact, Fiction, and Forecast". 4a ed. Cambridge, MA: Harvard University Press, 1983.

21 Nas palavras de Susan Haack: "Uma experiência é relevante para a justificação de suas crenças empíricas, mas não é preciso nenhuma classe privilegiada de crenças empíricas justificadas exclusivamente pelo apoio da experiência, independentemente do apoio de outras crenças" (Haack, 2009, p. 57). 
HAACK, Susan. "Evidence and Inquiry: a pragmatist reconstruction of epistemology". Expanded Edition. New York: Prometheus Books, 2009.

LEHRER, K. "Theory of Knowledge". London: Routledge, 1990. "Justification, coherence and knowledge". Erkenntnis, Vol. 50, Nr. 2/3, pp. 243-258, 1991.

. "Coherence, justification, and Chisholm". Philosophical Perspectives, Vol.

2, Epistemology, pp. 125-138, 1988.

OLSSON, E. "What is the problem of coherence and truth?" The Journal of Philosophy, Vol. 99, Nr. 5, pp. 246-272, 2002.

PETTIT, P. "The Common Mind: an essay on psychology, society, and politics". New York: Oxford University Press, 1993.

PUTNAM, H. "The Collapse of the Fact/Value Dichotomy and Other Essays". Cambridge, MA: Harvard University Press, 2004.

QUINE, W. V. "Two dogmas of empiricism". In: W. V. Quine. From a Logic Point of View. Cambridge, MA: Harvard University Press, 1953. pp. 20-46.

. "Ontological Relativity and Other Essays". New York: Columbia University Press, 1969.

RAWLS, J. "The independence of moral theory". In: J. Rawls. Collected Papers. Ed. S. Freeman. Cambridge, MA: Harvard University Press, 1999a. pp. 286-302. . "A Theory of Justice". Revised Edition. Cambridge, MA: Harvard University Press, 1999b.

. "Political Liberalism". New York: Columbia University Press, 1996.

ROBINSON, L. "Moral holism, moral generalism, and moral dispositionalism". Mind, Vol. 115, Nr. 458, pp. 331-360, 2006.

RUSSELL, B. "The Problems of Philosophy". London: Home University Library, 1912.

SCANLON, T. "What We Owe to Each Other". Cambridge, MA: Harvard University Press, 1998.

. "Being Realistic about Reasons". New York: Oxford University Press, 2014. SEARLE, J. "The Construction of Social Reality". New York: Free Press, 1995.

SIEGEL, H. "Justification by balance". Philosophical and Phenomenological Research, Vol. LII, Nr. 1, pp. 27-46, 1992.

SINGER, P. "Sidgwick and reflective equilibrium". The Monist, Vol. 58, 1974. Reprinted in: P. Singer. Unsanctifying Human Life. Ed. H. Kuhse. Oxford: Blackwell, 2002. pp. 27-50.

UN. "The Universal Declaration of Human Rights". [Online]. Disponível em: www. Un.org/en/docments/udhr/. (Acessado em 16 de junho de 2015). 